\title{
Analisis Implementasi Model Bisnis On Demand Service Mobile Platform Terhadap Tingkat Kepuasan Pelanggan Gojek Di Indonesia
}

\author{
Alfian Nara Weking ${ }^{1 *}$, Stefanus Ndala ${ }^{2}$ \\ ${ }^{1,2}$ Magister Teknik Informatika, Program Pascasarjana Universitas Atma Jaya Jogyakarta \\ ${ }^{1,2} \mathrm{Jln}$. Babarsari, Kota Yogyakarta, 55281, Indonesia \\ email: ${ }^{1}$ nara.weking89@gmail.com, ${ }^{2}$ stefanusndala87@gmail.com
}

Received: 30 Juli 2018; Revised: 2 Oktober 2018; Accepted: 20 Oktober 2018

Copyright (02018, Politeknik Harapan Bersama, Tegal

\begin{abstract}
The influence of the role of technology today, bringing competition in the business world will be more stringent over time. Technology in the modern world is a very important role in supporting the company's business processes that will have a positive impact on the company. For example, business people in the field of transportation. PT. Gojek Indonesia is one of the online services transportation business that utilizes mobile technology platform to support the business process model on demand service used by Gojek companies so that the services provided to customers run well and in line with expectations of business opportunities in Indonesia. Gojek companies are examples of startup companies in Indonesia that use mobile platform technology. In this study using descriptive method that starts with a survey to find the necessary data such as the data downloader of the Gojek application in the play store and the reviews or comments given by the customer to the application. These data will then be analyzed to see the level of satisfaction of customers or users of mobile platform-based services.
\end{abstract}

Abstrak - Pengaruh peran teknologi saat ini, membawa persaingan pada dunia usaha akan semakin ketat dari waktu ke waktu. Teknologi di dunia modern ini menjadi peran yang sangat penting dalam mendukung proses bisnis perusahaan yang akan berdampak positif bagi perusahaan tersebut. Misalnya, pelaku bisnis dibidang transportasi. PT. Gojek Indonesia adalah salah satu pelaku bisnis transportasi jasa online yang memanfaatkan teknologi mobile platform untuk mendukung model proses bisnis on demand service yang digunakan oleh perusahaan Gojek tersebut agar pelayanan yang diberikan kepada pelanggan berjalan dengan baik dan sesuai harapan terhadap peluang bisnis di Indonesia. Perusahaan Gojek adalah contoh perusahaan startup di Indonesia yang menggunakan teknologi mobile platform. Pada penelitian ini menggunakan metode deskriptif yang di mulai dengan melakukan survey untuk menemukan data-data yang diperlukan seperti data pengunduh aplikasi Gojek di play store dan ulasan-ulasan atau komentar yang diberikan oleh pelanggan terhadap aplikasi tersebut. Data-data tersebut kemudian akan di analisis untuk melihat tingkat kepuasan pelanggan atau pengguna layanan berbasis mobile platform.

*) Corresponding author: (Alfian Nara Weking)

Email: nara.weking89@gmail.com
Kata Kunci - On Demand Service, Mobile Plattform, Tingkat Kepuasan Pelanggan Gojek.

\section{PENDAHULUAN}

Pada masa kini teknologi internet merupakan sarana yang sangat membantu berbagai macam kegiatan manusia seperti komunikasi, toko online, bertransaksi bisnis dan lainnya.Sejak pertama diperkenalkan di Amerika pada tahun 1969, internet mengalami kemajuan yang luar biasa [1]. Pengaruh peran teknologi telah membawa persaingan pada dunia usaha akan semakin ketat dari waktu ke waktu. Dukungan teknologi terhadap proses bisnis pada perusahaan akan sangat berdampak positif bagi perusahaan tersebut. Dengan adanya peran teknologi tersebut dalam proses bisnis, perusahaan dalam memberikan pelayanan kepada pelanggan akan semakin cepat. Pada dasarnya suatu bisnis mempunyai tujuan untuk menciptakan pelanggan agar merasa puas terhadap pelayanannya.

Tjiptono (2005) menyatakan bahwa terciptanya kepuasan pelanggan dapat memberikan beberapa manfaat yaitu terciptanya hubungan yang harmonis antara perusahaan dan konsumennya, memberikan dasar yang baik bagi pembelian secara terus menerus dan terciptanya loyalitas pelanggan dan membentuk suatu rekomendasi dari mulut setiap orang yang menguntungkan bagi perusahaan [2]. Oleh sebab itu, tingkat kepuasan pelanggan merupakan hal yang menjadi penting bagi setiap pelaku bisnis, sebab pelayanan yang diberikan kepada pelanngan oleh pelaku bisnis akan meningkatkan kepuasan pelanggan itu tersendiri yang kemudian akan berdampak kepada loyalitas pelanggan sehingga pelanggan dapat mempercayai dan menggunakannya secara terus menerus. Tingkat kepuasan pelanggan dijadikan sebagai tolak ukur berhasil dan tidaknya terhadap pelaku dunia usaha dalam memberikan sebuah kualitas pelayanan [3].

On demand Service adalah sebuah pelayanan yang didasarkan atas sesuai dengan pemintaan pelanggan atau konsumen. Ketika ada konsumen yang memerlukan dan memesan jasa ojek online maka penyedia layanan akan langsung merespon. Konsep On demand Service juga sama seperti ketika kita memesan makanan cepat saji melalui delivery order [4]. 
PT. Gojek merupakan salah satu perusahaan jasa transportasi di Indonesia yang saat ini telah mengalami perkembangan menjadi layanan On demand Service berbasis teknologi Mobile Plattform online yang menyediakan berbagai layanan mulai dari transportasi, logistik, pembayaran, layan-antar makanan dan berbagai layanan $\mathrm{O} n$ demand lainnya.

\section{PENELITIAN YANG TERKAIT}

Aplikasi Mobile atau mobile platform merupakan sebuah perangkat lunak yang beroperasi pada perangkat mobile yang dapat digunakan dengan berpindah-pindah tempat dan mudah untuk dibawa kemana-mana. Aplikasi mobile juga dikenal sebagai aplikasi yang dapat diunduh dan memiliki fungsi tertentu sehingga menambah fungsionalitas dari perangkat mobile itu sendiri [5]. PT. Gojek Indonesia merupakan salah satu perusahaan yang memanfaatkan mobile platform yaitu berupa aplikasi untuk menjalankan bisnisnya di dibidang transportasi jasa. Para pelanggan atau pengguna dapat mengunduh aplikasi tersebut di play store android dan IOS Keberadaan aplikasi di Indonesia yang kemudian akan menjadi trend yaitu transportasi berbasis aplikasi yang dilirik sebagai model e-commerce dikarenakan transportasi sendiri merupakan hal yang dasar untuk kehidupan manusia dalam melakukan perpindahan dari suatu tempat ke tempat lain [6].

Bala Putra Dewa (2012) melakukan penelitian yang berjudul "Analisis dampak faktor customer relationship management dalam melihat tingkat kepuasan dan loyalitas pada pelanggan marketplace di Indonesia" kepuasan pelanggan terhadap layanan yang diberikan akan Berbanding lurus dengan tingkat loyalitas pelanggan [3].

Yang Yong (2010) melakukan penelitian yang berjudul "Korelasi antara Kepuasan Pelanggan dan Loyalitas Merek Layanan dengan Rasakan Kualitas" kepuasan pelanggan akan memberikan kontribusi untuk memahami pelanggan dan memebentuk loyalitas merek dan meningkatkan kualitas pelanggan [7].

Hasnelly (2011) dengan penelitian yang berjudul "Analisis Pendekatan Berbasis Sumberdaya pada Nilai Pelanggan dan Implikasi pada Loyalitas Pelanggan Organik Industri Produk" pemasaran adalah proses mengelola hubungan pelanggan menguntungkan dan dua target pemasaran, menarik pelanggan baru dengan menjanjikan nilai superior dan memelihara dan menumbuhkan pelanggan yang sudah ada dengan mengirimkan kepuasan [8].

\section{MODEL BISNIS DAN KEPUASAN PELANGGAN}

\section{A. Model Bisnis Gojek Berbasis Mobile Platform}

Menurut wikipedia.org, model bisnis merupakan sebuah pikiran mengenai bagaimana suatu organisasi menciptakan, memberikan, menangkap suatu nilai baik ekonomi maupun sosial. Model bisnis tersebut dipakai dalam ruang lingkup yang luas dengan konteks formal dan informal untuk menunjukkan aspek inti dari bisnis, termasuk mencakup maksud dan tujuan, apa yang ditawarkan, strategi, infrastruktur, struktur organisasi, praktik-praktik niaga, serta kebijakan-kebijaan dan proses-proses operasional. PT. Gojek Indonesia merupakan suatu perusahan yang bergerak di bidang transportasi jasa online dengan menggunakan model bisnis on demand service mobile platform untuk memberikan pelayanan kepada pelanggan atau konsumen di bidang tranportasi. Layanan sesuai dengan permintaan pelanggan ini diterapkan di driver ojek online berbasis platform mobile untuk mempermudah pelanggan dalam memesan layananlayanan yang ada di dalam aplikasi Gojek. [9].

\section{B. Kepuasan Pelanggan}

Menurut Greenberg, pelanggan merupakan seseorang individu atau kelompok yang membeli suatu produk berupa fisik maupun jasa dengan memikirkan factor keseimbangan harga, manfaat, kualitas dan jumlah berdasarkan keinginan mereka sendiri [3]. Sedangkan menurut Nasution, pelanggan adalah orang yang membeli sebuah produk yang diinginkan baik berupa barang ataupun jasa [3]. Dari penjelasan tersebut dapat diambil kesimpulan bahwa pelanggan merupakan seorang pelaku ataupun kelompok yang membeli suatu produk baik itu barang atau jasa sesuai dengan keinginannya. Menurut Kotler dan Keller mengungkapkan kepuasan adalah perasaan senang atau kecewa seseorang yang berasal dari perbandingan antara kesannya terhadap kinerja atau hasil suatu produk dan harapan harapannya. Lovelock dan Wright menyatakan bahwa, kepuasan adalah keadaan emosional, reaksi pascapembelian mereka, dapat berupa kemarahan, ketidakpuasan, kejengkelan, netralitas, kegembiraan dan kesenangan [10]. Dari penjelasan tersebut dapat disimpulkan bahwa kepuasan pelanggan adalah sebuah perasaan (gembira atau kecewa) yang berasal dari seorang pelanggan dan konsumen setelah membeli dan menggunakan produk baik barang maupun jasa.

\section{METODE PENELITIAN}

Metode deskriptif digunakan dalam penelitian ini yakni, mengidentifikasi adanya permasalahan yang signifikan untuk dipecahkan melalui metode deskriptif, membatasi dan merumuskan permasalahan secara jelas, menentukan tujuan dan manfaat penelitian, melakukan studi pustaka yang berkaitan dengan permasalahan, menentukan kerangka berfikir dan pertanyaan penelitian dan atau hipotesis penelitian, mendesain metode penelitian yang hendak digunakan termasuk menentukan populasi, sampel, teknik sampling, instrument pengumpulan data, dan menganalisis data, mengumpulkan, mengorganisasi, dan menganalisis data dengan menggunakan teknik statistik yang relevan, dan terakhir membuat laporan penelitian [3].

\section{A. Pengumpulan data}

Proses pengumpulan data yang diperlukan untuk mendukung penelitian ini adalah dengan melihat dan mengumpulkan ulasan atau service riview pada play store android dari pengguna aplikasi Gojek. Pada Tabel I diulas secara singkat bagaimana keluhan kepuasan pengguna terhadap PT. Gojek yang ada di Indonesia.

\section{B. Alur Layanan On Demand Service Go-jek}

Pada Gbr.1, alur layanan dijelaskan secara singkat mengenai pelanggan atau konsumen Gojek yang menggunakan transportasi jasa online Gojek. Pada Go-ride proses antar jemput, disini pelanggan mengirimkan lokasi tempat tinggal pada driver Gojek sehinggga drivernya tidak mengalami kesulitan pada saat proses penjemputan. Setelah 
itu pelanggan harus memberikan lokasi tujuan kepada driver agar dapat mengantar pelanggan sehingga tidak terjadi salah haluan atau lokasi. Sebaliknya pada Go-car dan Go-send. Sedangkan pada Go-food dimana proses pembelian makanan siap saji juga harus jelas lokasinya agar driver tidak menyasar pada tempat lain saat mencari restaurant atau cafe. Setelah itu masukan pilihan nama makanan yang akan dipesan oleh pelanggan yakni nama pengirim, penerima beserta nomor telponnya, setelah itu tinggal memesan [11].

Tabel I

CONTOH ULASAN PENGGUNA GOJEK

\begin{tabular}{|c|c|}
\hline $\begin{array}{c}\text { Code } \\
\text { Pengguna } \\
\text { Gojek } \\
\end{array}$ & Ulasan Online \\
\hline $\mathrm{P} 1$ & $\begin{array}{l}\text { Dengan keberadaan Go-jek ini, kami } \\
\text { dimanjakan oleh drivernya dalam hal } \\
\text { pelayanan, sepantasnya mereka pun } \\
\text { mendapatkan apa yang kami dapatkan dari } \\
\text { mereka. }\end{array}$ \\
\hline $\mathrm{P} 2$ & $\begin{array}{l}\text { Untuk Aplikasi Gojek ini memeng sangat } \\
\text { membantu kami karena pada saat berpergian } \\
\text { kemana-mana jadi mudah apalagi drivernya } \\
\text { sopan-sopan. }\end{array}$ \\
\hline $\mathrm{P} 3$ & $\begin{array}{l}\text { Memang lebih hemat menggunakan Gojek, } \\
\text { cuma apabila signal lagi jelek drivernya tidak } \\
\text { merespon, tapi untuk pelayanan sangat } \\
\text { memuaskan }\end{array}$ \\
\hline $\mathrm{P} 4$ & $\begin{array}{l}\text { Saya menggunakan jasa Gojek sudah } 2 \text { tahun } \\
\text { dan baik-baik saja. Dari drivernya baik } \\
\text { semua, tidak ada masalah. }\end{array}$ \\
\hline P5 & $\begin{array}{l}\text { Sebuah aplikasi yang bergerak di bidang jasa } \\
\text { dan transportasi online yg sangat membantu } \\
\text { dalam segalah urusan pekerjaan dan } \\
\text { kebutuhan lain-lain. }\end{array}$ \\
\hline P6 & $\begin{array}{l}\text { Membantu sekali dalam hal antar jemput. } \\
\text { Syukur dengan adanya aplikasi Gojek semua } \\
\text { masalah perjalanan jauh maupun dekat sangat } \\
\text { terbantu. }\end{array}$ \\
\hline P7 & $\begin{array}{l}\text { Hampir } 3 \text { tahun tekahir ini saya sudah sering } \\
\text { menggunakan aplikasi Gojek apalagi untuk } \\
\text { kebutuhan transportasi sehari-hari. Gofood } \\
\text { juga sudah dipakai beberapa kali. }\end{array}$ \\
\hline P8 & $\begin{array}{l}\text { Suka sekali sama Gojek, sudah hampir } \\
\text { setahun menggunakan gojek, selalu saja } \\
\text { memudahkan dalam segala aktivitas }\end{array}$ \\
\hline P9 & $\begin{array}{l}\text { Suka sekali sama aplikasi Gojek, semoga } \\
\text { sukses selalu tepat waktu dalam masalah } \\
\text { pesanan, harganyapun relative terjangkau }\end{array}$ \\
\hline P10 & $\begin{array}{l}\text { Senang sekali dengan adanya aplikasi Gojek } \\
\text { ini, dapat memudahkan perjalanan. Dan tetap } \\
\text { menjaga kepercayaan pelanggan. }\end{array}$ \\
\hline
\end{tabular}

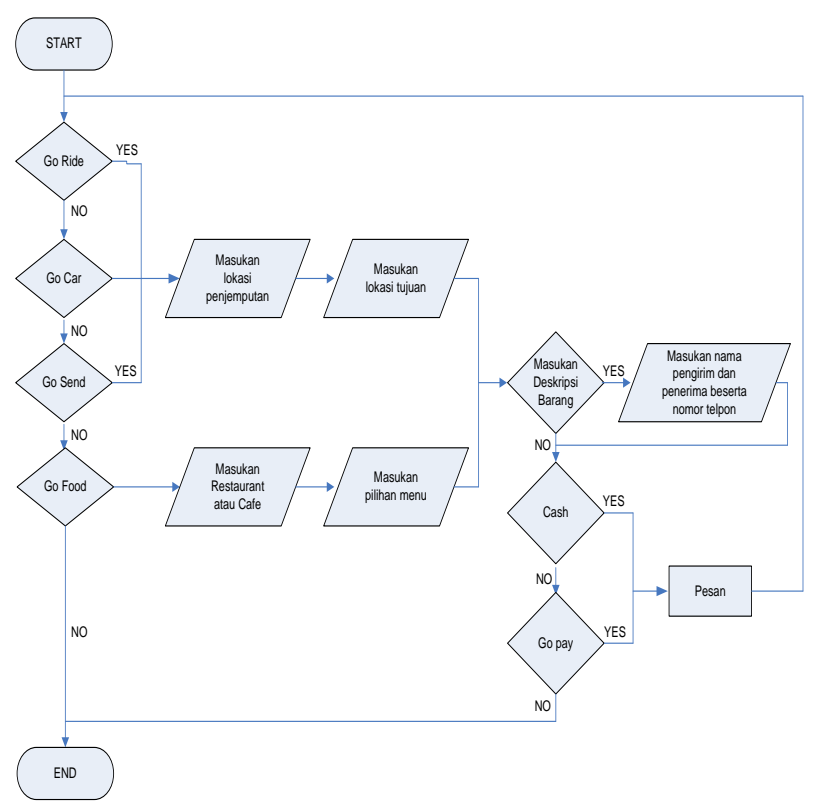

Gbr. 1 Alur Layanan On Demand Service Mobile Platform pada Gojek

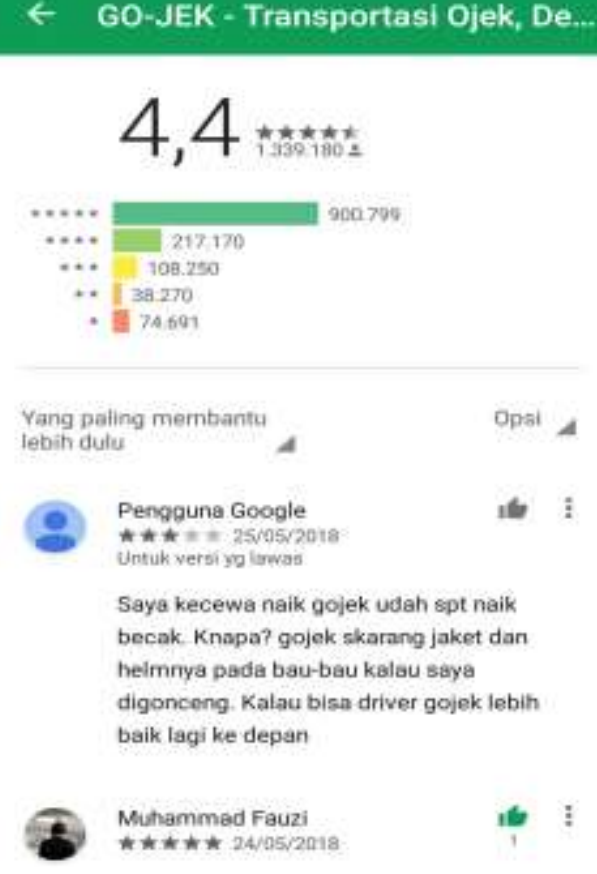

Gbr. 2 Sumber: Data Play Store Aplikasi Gojek

\section{B. Analisis Data}

Menganalisis data yang sudah didapat dari hasil pengumpulan data yang sudah dilakukan sebelumnya pada pengumpulan data terhadap transporasi jasa online Gojek dan pengguna atau pelanggan yang menggunakan transportasi online tersebut [6]. 
Dari Gbr.1, menunjukan bahwa total pengunduh aplikasi Gojek online terakhir 2018 sebanyak 1.339 .180 orang dengan nilai rating rata-rata 4.4 .

\section{HASIL DAN PEMBAHASAN}

\section{A. Statistik Deskriptif}

Dalam rangkah mengungkapkan tingkat kepuasan pelaggan pada transportasi jasa Gojek berbasis mobile platform, pemberian rating oleh penggunduh aplikasi Gojek sangat memberi pengaruh yang tinggi terhadap layanan tersebut.

TABEL II

PERSENTASE TINGKAT KEPUASAN PELANGGAN GOJEK ONLINE

\begin{tabular}{|c|c|c|c|}
\hline \multirow{2}{*}{$\begin{array}{c}\text { Rating } \\
\text { (Bintang) }\end{array}$} & Kategori & \multirow{2}{*}{$\begin{array}{l}\text { Frekuensi } \\
\text { (F) }\end{array}$} & \multirow{2}{*}{$\begin{array}{c}\text { Persentase } \\
(\%)\end{array}$} \\
\hline & $\begin{array}{c}\text { Tingkat Kepuasan } \\
\text { Pelanggan Gojek }\end{array}$ & & \\
\hline 5 & Sangat Puas & 900.799 & 67.26 \\
\hline 4 & Puas & 217.170 & 16.22 \\
\hline 3 & Cukup Puas & 108.250 & 8.08 \\
\hline 2 & Tidak Puas & 38.270 & 2.86 \\
\hline 1 & Sangat Tidak Puas & 74.691 & 5.58 \\
\hline \multicolumn{2}{|r|}{ Jumlah } & $1,339.180$ & 100.00 \\
\hline
\end{tabular}

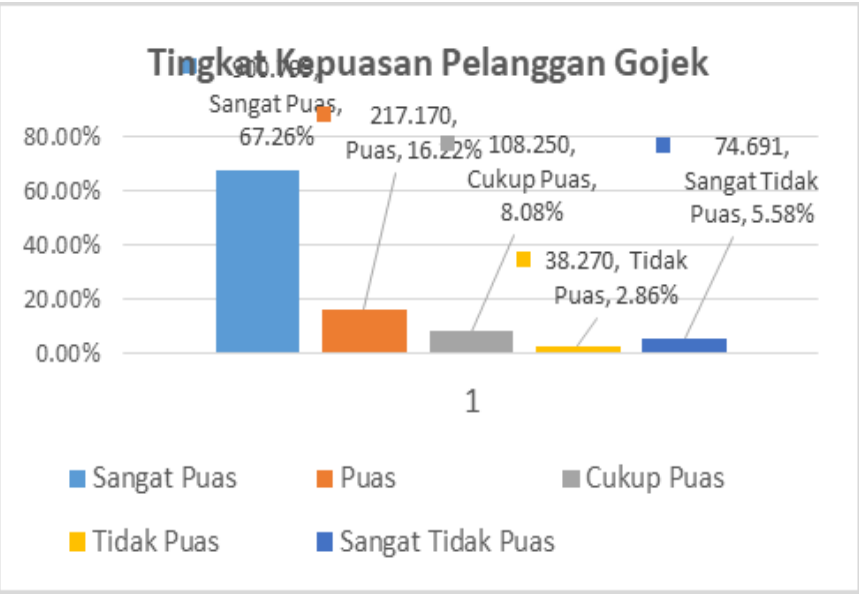

Gbr. 3 Grafik Tingkat Kepuasan Pengguna Aplikasi Gojek

Tabel II menunjukan bahwa sebagian besar penggunduh aplikasi memberikan nilai rating (bintang) 5 berkategori sangat puas dengan jumlah 900.799 atau $67.26 \%$, sedangkan sebagian kecil memberikan nilai rating 1 berkategori sangat tidak puas terhadap aplikasi Gojek dengan jumlah 74.691 atau $5.48 \%$. lebih jelasnya data tentang tingkat kepuasan pelanggan Gojek dapat dilihat dari grafik pada Gbr.3.

Berdasarkan Gbr.3, grafik menunjukan bahwa sebagian besar pengunduh aplikasi Gojek yang juga sebagai pelanggan atau konsumen Gojek yaitu 67.26\% dengan jumlah 900.799 orang yang memberikan nilai rating paling tinggi yaitu bintang 5 dan mengatakan atau memberikan ulasan mereka di aplikasi Gojek pada play store berkategori sangat puas. Dari jumlah presentase tersebut dapat mewakili sebagian besar pelanggan Gojek di Indonesia bahwa model bisnis on demand service mobile platform berpengaruhi sangat positif dan dapat meningkatkan kepuasan pelanggan.[12] Sedangkan selebihnya yaitu $16.22 \%$ denagn jumalah 217.170 orang mengatakan puas, dan $8.08 \%$ dengan jumlah 108.250 orang menyatakan cukup puas. $2.86 \%$ dengan jumlah 38.270 orang menyatakan tidak puas, dan $5.58 \%$ dengan jumlah 74.691 orang menyatakan dangat tidak puas, dengan mendapatkan nilai rating yang tinggi

\section{KESIMPULAN DAN SARAN}

Berdasarkan hasil analisis, maka dapat ditarik kesimpulan bahwa, implementasi model bisnis on demand service mobile platform dapat meningkatkan tingkat masih terjadi pada aplikasi Gojek mengingat jumlah pelanggan gojek sebanyak $2.86 \%$ menyatakan tidak puas dan $5.58 \%$ menyatakan sangat tidak puas dengan memberikan ulasan-ulasan terhadap aplikasi Gojek sangat mengecewakan.

kepuasan pelaggan Gojek di Indonesia. Hasil ini terbukti bahwa nilai rating ( 5 bintang) paling banyak diberikan oleh pelanggan Gojek berjumlah $900.799(67.26 \%)$ orang dan menyatakan ulasan mereka pada kolom komentar aplikasi Gojek di play store android sangat puas. Saran yang diberikan oleh penulis sesuai dengan hasil penelitian ini yaitu, agar segera diperbaiki bug-bug yang 5.58\% menyatakan sangat tidak puas dengan memberikan ulasanulasan terhadap aplikasi Gojek sangat mengecewakan.

\section{DAFTAR PUSTAKA}

[1] J. M. Rewah, "Pengaruh Kualitas Layanan Online Terhadap Kepuasan Pelanggan Telkomsel Manado," Cogito Smart J., vol. 2, no. 2, pp. 250-263, 2016

[2] W. Jayant, S. W. Utomo, and J. Murwani, "PENGARUH KUALITAS PELAYANAN TERHADAP TINGKAT KEPUASAN PELANGGAN PADA RUMAH MAKAN DI KABUPATEN NGAWI," J. Akunt. dan Pendidik., vol. 2, no. 1, pp. 60-70, 2013.

[3] B. P. Dewa and D. B. Setyohadi, "Analisis Dampak Faktor Customer Relationship Managementdalam Melihat Tingkat Kepuasan Dan Loyalitas Pada Pelanggan Marketplace Di Indonesia," Telematika, vol. 14, no. 1, pp. 33-38, 2017.

[4] S. D. Pendleton et al., "Multi-Class Autonomous Vehicles for Mobility-on-Demand Service," 2016.

[5] M. Irsan, "Rancang Bangun Aplikasi Mobile Notifikasi Berbasis Android untuk Mendukung Kinerja di Instansi Pemerintahan,” vol. 1, no. $1,2015$.

[6] N. Ronia Pangaribuan, N. M. Sofia Wijaya, and N. P. Eka Mahadewi, "Faktor-Faktor Yang Mempengaruhi Keputusan Wisatawan Menggunakan Transportasi Berbasis Aplikasi Di Pt. Gojek Indonesia," J. IPTA, vol. 4, no. 2, p. 64, 2016.

[7] Y. Yong, "Research on Correlation between Customer Satisfaction and Brand Loyalty of Service with Experience Qualities," pp. 3-6, 2010 .

[8] F. Technology, I. Lecturer, P. Universities, and I. V Region, “Analysis of Resource Based Approach on The Customer Value and Customer Satisfaction and Its Implications on Customer Loyalty of Organic Products Industry."

[9] C. S. Go-jek and G. Motorcycle, "Brand Image Analysis of Online Ojek Apps Service," no. November, pp. 288-293, 2017.

[10] J. E. Panjaitan and A. L. Yuliati, "PENGARUH KUALITAS PELAYANAN TERHADAP KEPUASAN PELANGGAN PADA JNE CABANG BANDUNG," DeReMa J. Manaj., vol. 11, no. 2, pp. 265-289, 2016.

[11] T. Peng, Q. Liu, and G. Wang, "in Location-Based Services," no. Id, pp. 1-12, 2014

[12] M. Service, "Autonomous Personal Mobility Scooter for Multi-Class," pp. 1753-1760, 2016. 